\title{
Septic Arthritis of the Temporomandibular Joint without an Apparent Source of Infection: A Case Report
}

\author{
Daisuke Suda, Hiroyuki Takatsuji, Naoaki Saito, Akinori Funayama, Kanae Niimi, \\ Tadaharu Kobayashi
}

Division of Reconstructive Surgery for Oral and Maxillofacial Region, Graduate School of Medical and Dental Sciences, Niigata University, Niigata, Japan

Email: d-suda@dent.niigata-u.ac.jp

How to cite this paper: Suda, D., Takatsuji, H., Saito, N., Funayama, A., Niimi, K. and Kobayashi, T. (2017) Septic Arthritis of the Temporomandibular Joint without an Apparent Source of Infection: A Case Report. Open Journal of Stomatology, 7, 242249 .

https://doi.org/10.4236/ojst.2017.74018

Received: March 24, 2017

Accepted: April 27, 2017

Published: April 30, 2017

Copyright $\odot 2017$ by authors and Scientific Research Publishing Inc. This work is licensed under the Creative Commons Attribution International License (CC BY 4.0).

http://creativecommons.org/licenses/by/4.0/

\begin{abstract}
Septic arthritis of the temporomandibular joint (TMJ) is a rare disease that is characterized by preauricular pain, edema, malocclusion, trismus and abscess formation in the TMJ region. An 85-year-old male visited our hospital with the complaint of left-sided TMJ swelling, pain and trismus. Septic arthritis of the left TMJ was diagnosed on the basis of considerable elevation of CRP (Creactive proteins) and CT imaging findings. The patient was treated with oral Faropenem at $450 \mathrm{mg}$ daily, but CRP increased three days after the initial visit. He was hospitalized and treated with intravenous administration of cefazolin at $2 \mathrm{~g}$ and clindamycin at $1.2 \mathrm{~g}$ daily for six days. Propionibacterium species and Veillonella species grew in a culture of the joint aspirate, but there was no apparent source of infection. After acute infectious symptoms had passed, the patient was treated with oral amoxicillin at $750 \mathrm{mg}$ daily for eight weeks and was instructed to do jaw opening exercise. The patient was discharged on the 11th hospital day. After three weeks of the hospital discharge, the patient healed completely. To avoid serious complications, clinicians should include septic arthritis of the TMJ in the differential diagnosis of preauricular pain, trismus and swelling.
\end{abstract}

\section{Keywords}

Septic Arthritis, Temporomandibular Joint, No Apparent Source of Infection

\section{Introduction}

Septic arthritis of the temporomandibular joint (TMJ) is a rare disease that is characterized by preauricular pain, edema, malocclusion, trismus and abscess for- 
mation in the TMJ region. Early diagnosis and treatment are essential to avoid possible complications such as dissemination of infection, joint dysfunction, growth disturbances, fibrosis, and ankyloses [1] [2] [3] [4]. The pathogeneses of the infections include hematogenous dissemination from a distant site, local spread and direct inoculation [5] [6] [7] [8] [9]. In this paper, a case of septic arthritis of the TMJ without an apparent source of infection is described.

\section{Case Report}

An 85-year-old male visited our hospital with the complaint of left-sided TMJ swelling, pain and trismus over the past several weeks. Although a primary dentist administered an antibiotic agent, the symptoms did not improve. He had medical histories of paroxysmal atrial fibrillation, hypertension, hyperlipemia and diabetes mellitus, old myocardial infarction, cataracta and spinal canal stenosis.

A physical examination revealed obvious swelling, redness and tenderness of the left preauricular area (Figure 1). Maximum mouth opening was limited to $20 \mathrm{~mm}$ without deviation of the mandible. The gingiva, tongue, and oral mucous membrane showed no inflammatory signs except for percussion pain of the left lower second molar tooth. The patient had a slight fever of $37.0^{\circ} \mathrm{C}$ and his vital signs were normal. Results of laboratory studies were as follows: hematocrit, $43.2 \%$ (normal, $35.6 \%$ to $45.4 \%$ ); hemoglobin, $14.6 \mathrm{~g} / \mathrm{dl}$ (normal, 10.8 to 14.9 $\mathrm{g} / \mathrm{dl}$ ); red blood cell count, $465 \times 10^{4} / \mathrm{mm}^{3}$ (normal, 3.78 to $4.99 \times 10^{6} / \mu \mathrm{l}$ ); white blood cell count, 5650/ $\mu \mathrm{l}$ (normal, 3040 to $8540 / \mu \mathrm{l}$ ); C-reactive protein (CRP), $8.53 \mathrm{mg} / \mathrm{dl}$ (normal, less than $0.3 \mathrm{mg} / \mathrm{dl}$ ); Rheumatoid factor, $7.41 \mathrm{IU} / \mathrm{ml}$ (nor$\mathrm{mal}$, less than $15 \mathrm{U} / \mathrm{ml}$ ); and hemoglobin A1c (HbAlc), 6.8\% (normal, 4.6 to 6.2\%) (Table 1).

A panoramic radiograph showed coarsening of the trabecular pattern of the left condyle (Figure 2), and computed tomography (CT) images showed diffuse

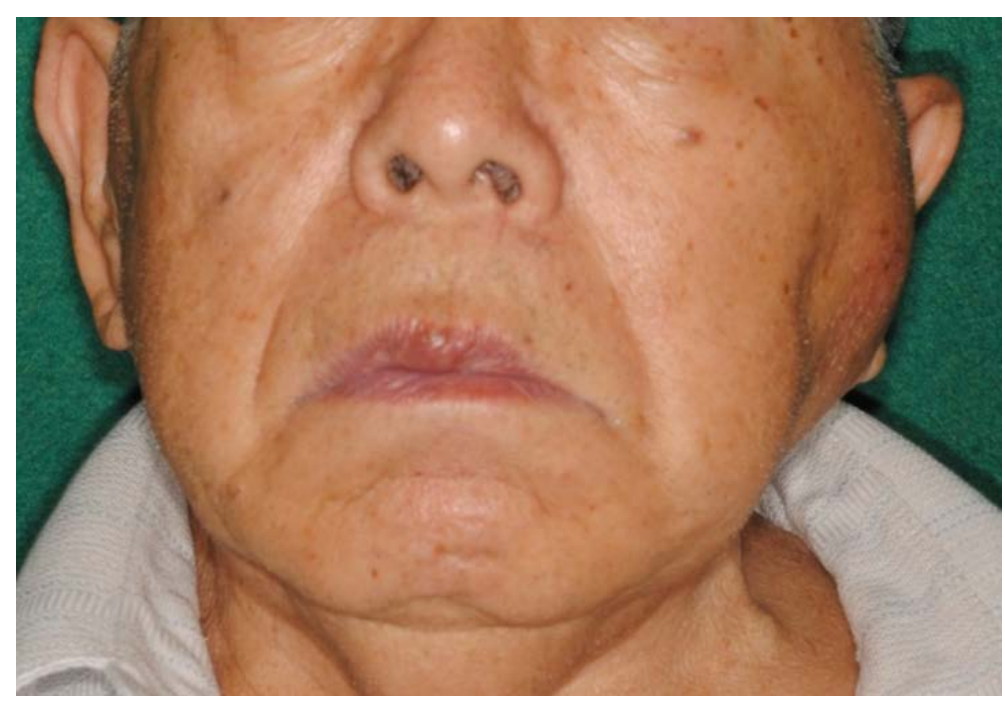

Figure 1. Clinical findings at the initial visit. Obvious swelling, redness and tenderness of the left preauricular area were recognized. 
Table 1. Hematological findings at the initial visit.

\begin{tabular}{ccc}
\hline Test & Value & Normal value range \\
\hline Red blood cells & $4.65 \times 10^{6} / \mu \mathrm{l}$ & $3.78-4.99 \times 10^{6} / \mu \mathrm{l}$ \\
Haemoglobin $(\mathrm{Hb})$ & $14.6 \mathrm{~g} / \mathrm{dl}$ & $10.8-14.9 \mathrm{~g} / \mathrm{dl}$ \\
Hematocrit $(\mathrm{Hct})$ & $43.2 \%$ & $35.6 \%-45.4 \%$ \\
Platelets & $24.3 \times 10^{4} / \mu \mathrm{l}$ & $15.0-36.1 \times 10^{4} / \mu \mathrm{l}$ \\
White blood cells & $5650 / \mu \mathrm{l}$ & $3040-8540 / \mu \mathrm{l}$ \\
CRP & $8.53 \mathrm{mg} / \mathrm{dl}$ & $\uparrow$ \\
APTT & $51.3 \mathrm{sec}$ & Less than $0.3 \mathrm{mg} / \mathrm{dl}$ \\
PT-INR & 1.46 & - \\
ASO & $50.8 \mathrm{IU} / \mathrm{ml}$ & \\
RF & $7.4 \mathrm{IU} / \mathrm{ml}$ & \\
HbAlc & $6.8 \%$ & \\
ALP & $299 \mathrm{IU} / \mathrm{l}$ & \\
\hline
\end{tabular}

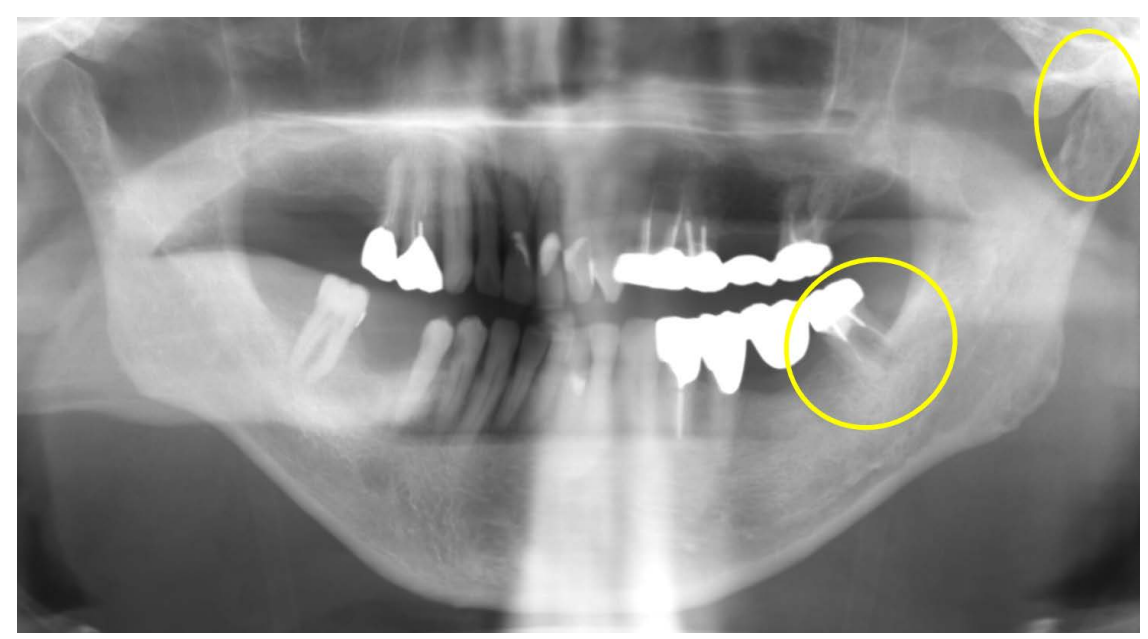

Figure 2. Orthopantomography at the initial visit. Coarsening of the trabecular pattern of the left condyle was observed.

soft-tissue swelling involving the preauricular region, a poorly marginated abscess surrounding the left condyle, a mixture of bone lysis and sclerosis of the left condyle, and bone sclerosis surrounding the left lower second molar tooth (Figure 3). A diagnosis of septic arthritis of the left TMJ was made.

He was treated with oral Faropenem at $450 \mathrm{mg}$ daily, but CRP increased to $11.0 \mathrm{mg} / \mathrm{dl}$ three days after the initial visit. He was hospitalized and treated with intravenous administration of cefazolin at $2 \mathrm{~g}$ and clindamycin at $1.2 \mathrm{~g}$ daily for six days. Propionibacterium species and Veillonella species grew in a culture of the joint aspirate (Figure 4), but there was no apparent source of infection with the exception of asymptomatic bone sclerosis surrounding the left lower second molar tooth. Although concentration of $99 \mathrm{mTc}$ was recognized in the thoracic spine and cervical spine by whole body bone scintigraphy on the ninth hospital day, an orthopedic specialist decided that it was unrelated to the cause of infection. 


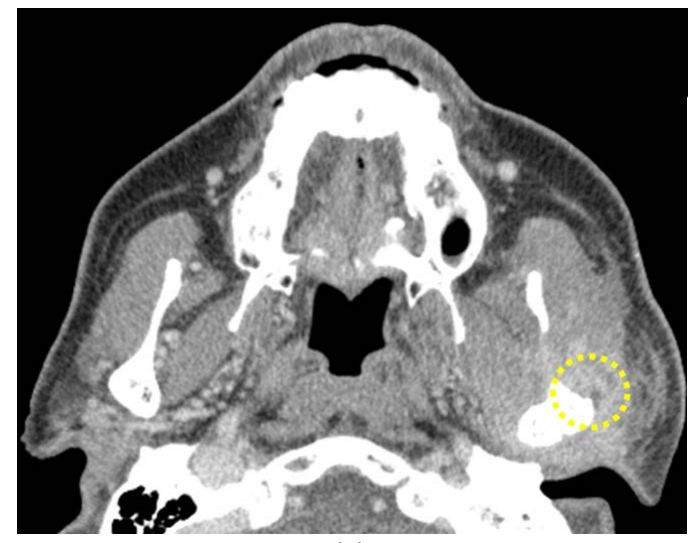

(a)

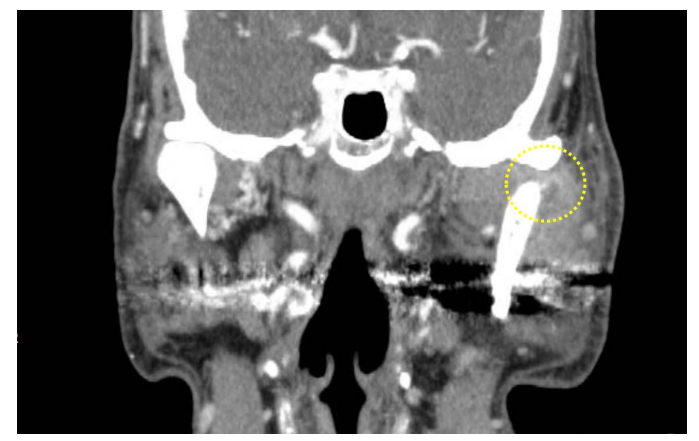

(b)

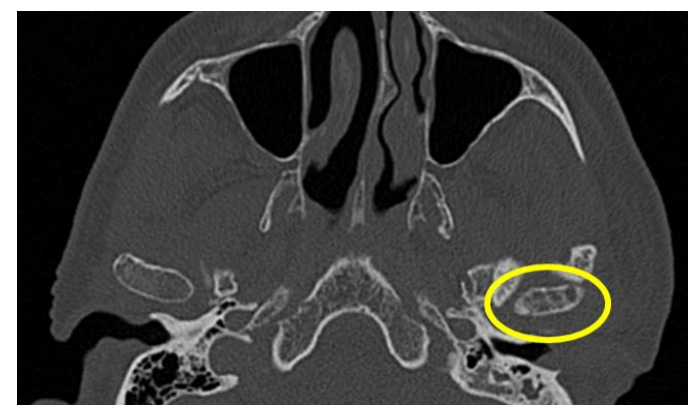

(c)

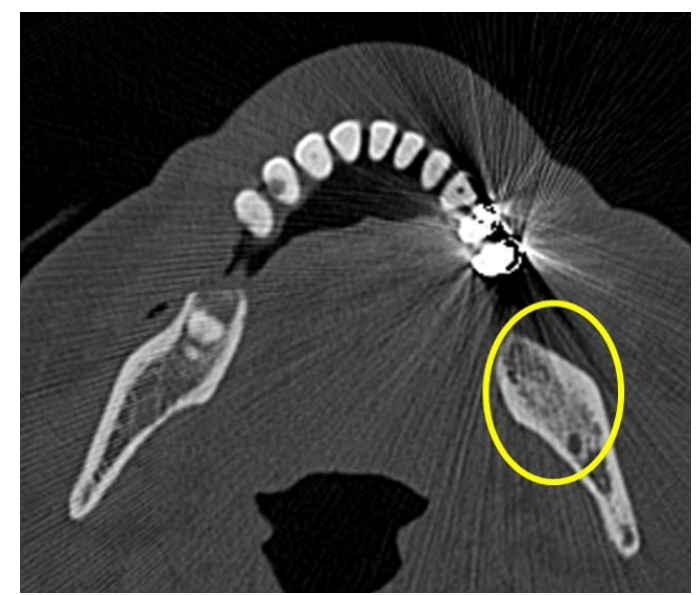

(d)

Figure 3. CT images at the initial visit: (a) (b) diffuse soft-tissue swelling involving the preauricular region and a poorly marginated abscess surrounding the left condyle, (c) a mixture of bone lysis and sclerosis of the left condyle, and (d) bone sclerosis surrounding the left lower second molar tooth. 


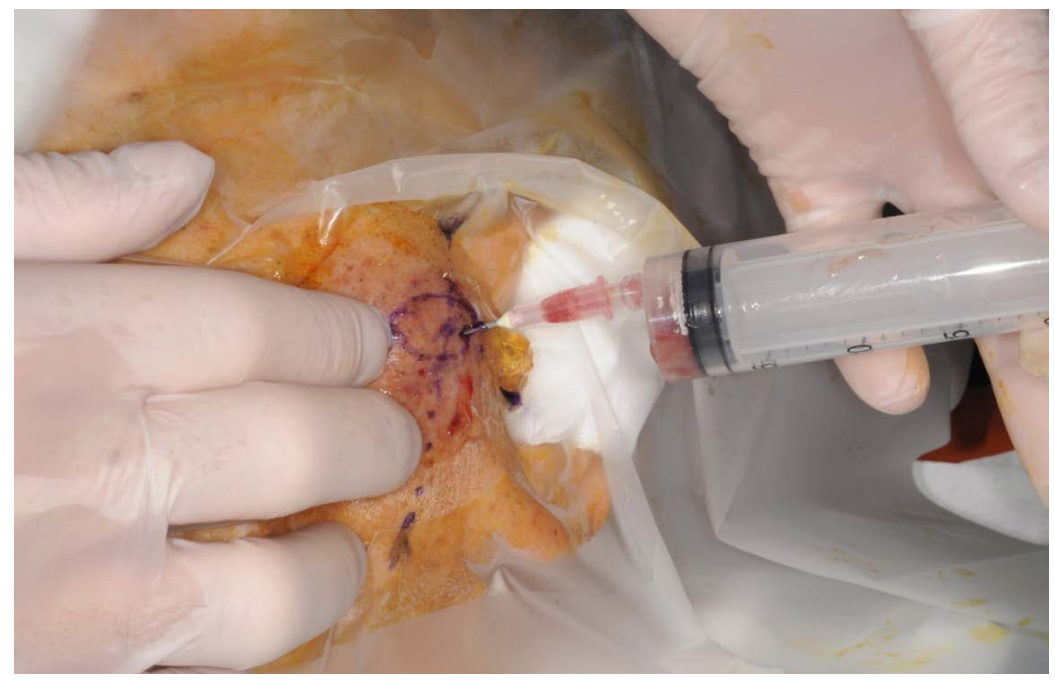

Figure 4. Needle aspiration of the abscess surrounding the left condyle.

After acute infectious symptoms had passed on the seventh hospital day, the patient was treated with oral amoxicillin at $750 \mathrm{mg}$ daily for eight weeks and was instructed to do jaw opening exercise. The patient was discharged on the 11th hospital day. After three months of hospital discharge, the patient had no symptom of swelling, redness and trismus (Figure 5).

\section{Discussion}

Septic arthritis of the TM joint most often occurs in male adults, but it has been reported in infants and children [1] [8] [9] [10]. The most common presenting complaints in septic arthritis of the TMJ are trismus and pain, although swelling, tenderness, erythema and malocclusion with ipsilateral posterior open-bite have also been reported [2] [7] [8]. Patients may present malaise and fever. The serum leukocyte count may be normal or increased, and CRP level is a good indicator of disease severity [6] [10]. However, a diagnostic delay problem was reported and the reasons were discussed [1] [6] [10]. Local inflammatory signs of septic arthritis of the TMJ are nonspecific and might be insidious because of the anatomic location of the TMJ deep to the parotid gland and the masseter. Systemic manifestations might be few and widespread antibiotic usage for unrelated conditions can cure some early but undiagnosed cases. In the present case, local findings including trismus, tenderness and edema were not severe and were nonspecific, and systemic inflammatory signs such as fever, leukocytosis and tachycardia were absent, though there was considerable elevation of CRP, and CRP level was a good indicator of disease severity.

In the differential diagnosis of septic arthritis of the TMJ from other diseases, findings of CT and/or MRI play a key role because CT and MRI scans visualize bone and soft tissue with excellent resolution and are noninvasive [8]. In the present case, the abscess surrounding the left condyle and a mixture of bone lysis and sclerosis of the left condyle on CT images were decisive in diagnosing septic arthritis of left TMJ. 


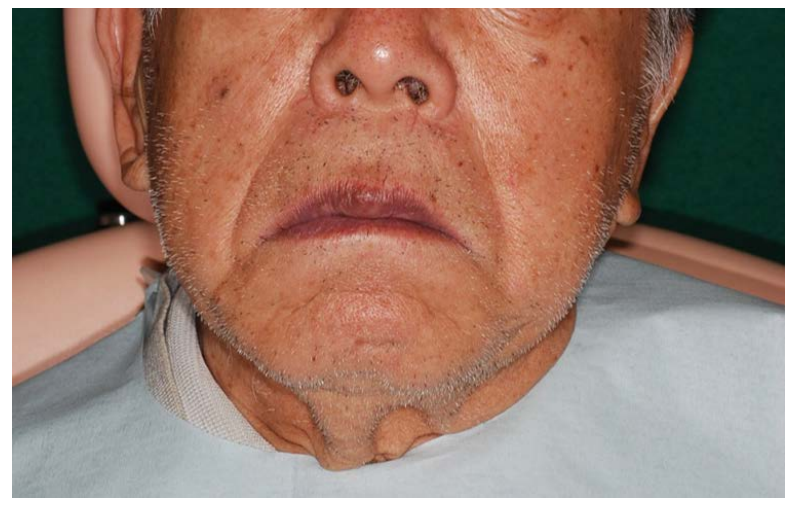

Figure 5. Clinical findings, three months after the treatment.

There are three routes of bacteria to the TMJ: hematogenous dissemination from a distant site, local spread and direct inoculation [5] [6] [7] [8] [9]. The TMJ might be inherently vulnerable to hematogenous dissemination from a distant site because the high vascularity of its synovial membrane allows greater exposure to bacteria [11]. Contiguous spread of infection is common after dental procedures [6] [11], parotiditis, mastoiditis or otitis [12]. Direct inoculations occur secondarily to arthrocentesis, arthroscopy or acupuncture [13].

Risk factors for the development of septic arthritis can be divided into local and systemic factors [9]. Local factors include blunt trauma, previous joint disease (osteoarthritis, internal derangement), and burn wounds. In patients with these local factors, alteration of the joint architecture and formation of a hematoma might predispose the TMJ to infection. Systemic factors include autoimmune diseases, diabetes mellitus, medications such as steroids or immunosuppressants, and sexually transmitted diseases, which are related to compromised immune systems. However, the source of infection sometimes remains unknown as in the present case.

Staphylococcus aureus, Staphylococcus saprophyticus, Neisseria gonorrhea, Streptococcus viridans, and Haemophilusinfluenzae have been reported as common infecting organisms in septic arthritis of the TMJ [1] [8] [10]. In our case, however, Propionibacterium species and Veillonella species were identified by culture of the joint aspirate. Propionibacterium species are Gram-positive anaerobic bacteria and are part of the natural microbial flora of the skin, urogenital tract and intestine. Veillonella species are Gram-negative anaerobic bacteria and have been frequently isolated from human oral cavities.

Irrigation and drainage, antibiotic therapy, and joint rest have been recommended for the treatments of septic arthritis of the TMJ in previous reports. Several studies have shown positive results from arthrocentesis for irrigation and drainage of the joint space [6] [7] [8]. Empiric antibiotic therapy should be initiated immediately after diagnosis, and appropriate modifications to the antibiotic regimen should be made after gram stains and cultures of the joint aspirate. During the acute phase of infection, the TMJ should be rested. Jaw opening exercise should be started after the acute phase of infection has passed [1] [9].

Although most patients with septic arthritis of the TMJ have complete recov- 
ery after treatment, possible complications should be considered [5]. Since delayed treatment of septic arthritis can result in serious complications, including dissemination of infection, joint dysfunction, growth disturbances, fibrosis, and ankyloses [1] [2] [3] [4], clinicians should include septic arthritis of the TMJ in the differential diagnosis of preauricular pain, trismus and swelling if there was no apparent source of infection.

\section{Conclusion}

We report a case of septic arthritis of the TMJ without an apparent source of the infection. To avoid serious complications, septic arthritis of the TMJ should be considered in all patients with preauricular pain, trismus and swelling.

\section{References}

[1] Leighty, S.M., Spach, D.H., Myall, R.W. and Burns, J.L. (1993) Septic Arthritis of the Temporomandibular Joint: Review of the Literature and Report of Two Cases in Children. International Journal of Oral and Maxillofacial Surgery, 22, 292-297. https://doi.org/10.1016/S0901-5027(05)80519-3

[2] Bounds, G.A., Hopkins, R. and Sugar, A. (1987) Septic Arthritis of the Temporomandibular Joint-A Problematic Diagnosis. British Journal of Oral and Maxillofacial Surgery, 25, 61-67. https://doi.org/10.1016/0266-4356(87)90158-6

[3] Goodman, W.S. and Strelzow, V.V. (1979) Infections of the Temporomandibular Joint. Journal of Otolaryngology, 8, 250-254.

[4] Topazian, R.G. (1964) Etiology of Ankylosis of the Temporomandibular Joint: Analysis of 44 Cases. Journal of Oral Surgery, Anesthesia, and Hospital Dental Service, 22, 227-233.

[5] Goldschmidt, M.J., Butterfield, K.J., Goracy, E.S. and Goldberg, M.H. (2002) Streptococcal Infection of the Temporomandibular Joint of Hematogenous Origin: A Case Report and Contemporary Therapy. Journal of Oral and Maxillofacial Surgery, 60, 1347-1353. https://doi.org/10.1053/joms.2002.35736

[6] Sembronio, S., Albiero, A.M., Robiony, M., Costa, F., Toro, C. and Politi, M. (2007) Septic Arthritis of the Temporomandibular Joint Successfully Treated with Arthroscopic Lysis and Lavage: Case Report and Review of the Literature. Oral Surgery Oral Medicine Oral Pathology Oral Radiology, 103, e1-e6. https://doi.org/10.1016/j.tripleo.2006.08.028

[7] Cai, X.Y., Yang, C., Chen, M.J., Zhang, S.Y. and Yun, B. (2010) Arthroscopic Management of Septic Arthritis of Temporomandibular Joint. Oral Surgery Oral Medicine Oral Pathology Oral Radiology, 109, 24-30. https://doi.org/10.1016/j.tripleo.2009.08.007

[8] Cai, X.Y., Yang, C., Zhang, Z.Y., Qiu, W.L., Chen, M.J. and Zhang, S.Y. (2010) Septic Arthritis of the Temporomandibular Joint: A Retrospective Review of 40 Cases. Journal of Oral and Maxillofacial Surgery, 68, 731-738. https://doi.org/10.1016/j.joms.2009.07.060

[9] Gams, K. and Freeman, P. (2016) Temporomandibular Joint Septic Arthritis and Mandibular Osteomyelitis Arising from an Odontogenic Infection: A Case Report and Review of the Literature. Journal of Oral and Maxillofacial Surgery, 74, 754763. https://doi.org/10.1016/j.joms.2015.11.003

[10] Gayle, E.A., Young, S.M., McKenna, S.J. and McNaughton, C.D. (2013) Septic Arthritis of the Temporomandibular Joint: Case Reports and Review of the Literature. 
The Journal of Emergency Medicine, 45, 674-678. https://doi.org/10.1016/j.jemermed.2013.01.034

[11] Lohiya, S. and Dillon, J. (2016) Septic Arthritis of the Temporomandibular JointUnusual Presentations. Journal of Oral and Maxillofacial Surgery, 74, 87-94. https://doi.org/10.1016/j.joms.2015.06.166

[12] Mardinger, O., Rosen, D. and Minkow, B. (2003) Temporomandibular Joint Involvement in Malignant External Otitis. Oral Surgery Oral Medicine Oral Pathology Oral Radiology, 96, 398-403. https://doi.org/10.1016/S1079-2104(03)00471-2

[13] Matsumura, Y., Inui, M. and Tagawa, T. (1998) Peritemporomandibular Abscess as a Complication of Acupuncture: A Case Report. Journal of Oral and Maxillofacial Surgery, 56, 495-496. https://doi.org/10.1016/S0278-2391(98)90721-2

Submit or recommend next manuscript to SCIRP and we will provide best service for you:

Accepting pre-submission inquiries through Email, Facebook, LinkedIn, Twitter, etc. A wide selection of journals (inclusive of 9 subjects, more than 200 journals) Providing 24-hour high-quality service User-friendly online submission system Fair and swift peer-review system Efficient typesetting and proofreading procedure Display of the result of downloads and visits, as well as the number of cited articles Maximum dissemination of your research work

Submit your manuscript at: http://papersubmission.scirp.org/

Or contact ojst@scirp.org 